\title{
Adherence to wearing therapeutic shoes among people with diabetes: a systematic review and reflections
}

This article was published in the following Dove Press journal:

Patient Preference and Adherence

8 August 2016

Number of times this article has been viewed

\author{
Gustav Jarl ${ }^{1,2}$ \\ Lars-Olov Lundqvist ${ }^{2}$ \\ 'Department of Prosthetics and \\ Orthotics, Faculty of Medicine and \\ Health, ${ }^{2}$ University Health Care \\ Research Center, Faculty of Medicine \\ and Health, Örebro University, \\ Örebro, Sweden
}

Introduction: Therapeutic shoes are prescribed to prevent diabetic foot ulcers, but adherence to wearing the shoes is often poor.

Aim: The aim of this study was to review the literature on factors that are associated with adherence to wearing therapeutic shoes and construct a model of adherence to aid future research and development in the field.

Methods: We conducted a systematic search in PubMed, CINAHL, and PsycINFO for quantitative studies on factors associated with adherence to wearing therapeutic shoes among people with diabetes.

Results: Six studies were included in the review. The studies focused mainly on patient-, therapy-, and condition-related adherence factors. There is some evidence (three to five studies) that sex, diabetes duration, and ulcer history are not associated with adherence. The evidence for or against the other factors was weak (only one or two studies) or conflicting.

Conclusion: There is no conclusive evidence for using any factor to predict adherence to wearing therapeutic shoes, but there is some evidence against using certain factors for predicting adherence. Future studies should include a broader range of factors, including health system and social/economic factors, and they should investigate perceived costs and benefits of wearing therapeutic shoes in comparison with other shoes or no shoes. A seesaw model is presented illustrating the complex phenomenon of adherence. Further research is needed to identify factors associated with adherence to wearing therapeutic shoes, to enable the development of interventions to improve adherence and thereby reduce ulceration rates among people with diabetic foot complications.

Keywords: Patient compliance, shoes, foot ulcer, diabetic foot, diabetes complications, diabetic neuropathies

\section{Introduction}

Redistributing pressures under the diabetic foot is essential to prevent and heal plantar ulcers. However, several studies have reported that people with diabetes tend to wear their offloading devices, such as walkers, half-shoes, and therapeutic shoes, less than would be advisable. ${ }^{1-7}$ Therefore, guidelines recommend using nonremovable devices, such as total contact casts, to offload pressure on ulcers. ${ }^{8,9}$ However, it is not feasible to use nonremovable devices once the ulcer has healed and often therapeutic shoes are prescribed to prevent reulceration. High reulceration rates have been reported in the literature ${ }^{10-12}$ and low adherence to wearing the therapeutic shoes might be one explanation. ${ }^{2}$ Thus, there is a need to understand the reasons for the low adherence to wearing therapeutic shoes to be able to improve it and thereby reduce ulceration rates among people with diabetes.
Correspondence: Gustav Jarl Department of Prosthetics and Orthotics, University Hospital Örebro, S-70I 85 Örebro, Sweden

$\mathrm{Tel}+46196025875$

Fax +4619122010

Email gustav.jarl@regionorebolan.se $\mathrm{BY}$
hC hereby accept the Terms. Non-commercial uses of the work are permitted without any further permission from Dove Mediect
for commercial use of this work, please see paragraphs 4.2 and 5 of our Terms (https://www.dovepress.com/terms.php). 
The World Health Organization defines adherence as "the extent to which a person's behavior - taking medication, following a diet, and/or executing lifestyle changes - corresponds with agreed recommendations from a health care provider."13 This definition emphasizes the person's agreement to the recommendations, in contrast to the older term compliance, which suggests obedience to expert advice. People cannot simply be expected to follow their treatment regimen (and blamed if they do not), as a number of factors will affect their behavior and capacity to adhere. Adherence is thus a multidimensional concept, proposed to consist of five interconnected dimensions: 1) patient-related factors; 2) therapy-related factors; 3) condition-related factors; 4) health system-related factors; and 5) social and economic factors. ${ }^{13}$

When people are asked about their therapeutic shoes, common complaints and reasons for not wearing them are that the shoes are found to be unattractive, too big, uncomfortable, or difficult to walk in.,14-16 These reasons are well known to clinicians prescribing therapeutic shoes, but there might be other, less obvious, factors that influence an individual's decision to wear or not wear therapeutic shoes. These factors might include perceived severity of the foot condition, sensory neuropathy, and beliefs about what causes foot ulcers. Such reasons are not always obvious to the person with the foot condition and would therefore not be mentioned in interviews. Thus, there is a need to complement qualitative studies and clinical experience with quantitative studies that can reveal other factors that influence adherence, and thereby get a broader picture of the complex phenomenon of adherence to wearing therapeutic shoes.

The aim of this study was to review and discuss the current quantitative literature on factors associated with adherence to wearing therapeutic shoes among people with diabetes and construct a model of adherence to support future research and development in the field.

\section{Methods}

We searched PubMed, CINAHL, and PsycINFO in June 2016 from their inception. The language was restricted to English.
Search details are presented in Table 1. The abstracts of all articles were read by one of the authors (GJ) and both authors read the full text of the articles that were relevant for the purpose of this review. Studies were included only if they included a statistical investigation of factors associated with adherence to wearing therapeutic shoes among people with diabetes.

\section{Results and reflections}

The search yielded 46 unique articles. One of the authors (GJ) read the abstracts (or full text, if no abstract was available) and excluded 34 articles that did not fulfill the inclusion criterion. Both authors read the full text of the 12 remaining and potentially relevant articles and excluded six more articles that did not fulfill the inclusion criterion. Thus, six articles were included in the review (Table 2). The studies investigated adherence with regard to factors related to the patient's perceptions, the condition, the therapy, the patient's social and economic circumstances, and the health system, with the main focus on patient-, therapy-, and condition-related factors.

\section{Description of included studies}

Arts et a ${ }^{17}$ studied 153 people with peripheral neuropathy and a recently healed plantar foot ulcer, and investigated the association between self-reported adherence and demographic variables, perceptions of the shoes and other factors in a multiple regression analysis. Participants were considered adherent ("frequent users") if they wore therapeutic shoes for at least $60 \%$ of daytime hours.

Breuer ${ }^{18}$ interviewed people with peripheral neuropathy and a healed ulcer. Fifty-one of the 85 interviewees were considered adherent, defined as wearing therapeutic shoes on the day of interview, and 34 were considered nonadherent. Characteristics of the participants and answers on a questionnaire were compared between the adherent and nonadherent groups.

Chantelau and Haage ${ }^{3}$ interviewed 51 people attending a diabetic foot clinic. Sex, ulcer history, and frequency of foot

Table I Search methods and results

\begin{tabular}{|c|c|c|}
\hline Database & Search strings & Number of hits \\
\hline \multirow[t]{2}{*}{ PubMed } & "Diabetes mellitus" (MeSH terms) AND "patient compliance" (MeSH terms) AND & 23 \\
\hline & ("shoes" [MeSH terms] OR "orthotic devices" [MeSH terms]) AND English[language] & \\
\hline \multirow[t]{3}{*}{$\mathrm{CINAHL}$} & ([MH “Diabetes Mellitus, Type 2"] OR [MH “Diabetes Mellitus, Type I"] OR [MH “Diabetes & 32 \\
\hline & Mellitus"] OR [MH “Diabetic Patients"] OR [MH “Diabetic Foot”]) AND ([MH “Shoes"] & \\
\hline & OR [MH "Orthopedic Footwear"]) AND (MH "Patient Compliance") & \\
\hline \multirow[t]{3}{*}{ PsyclNFO } & "Diabetes mellitus" [MeSH terms] AND "patient compliance" [MeSH terms] AND English & 0 \\
\hline & [language limiter] AND (“shoes” [MeSH terms] OR “orthotic devices” [MeSH terms]) & \\
\hline & Unique articles & 46 \\
\hline
\end{tabular}

Note: aRestricted to English language articles.

Abbreviations: $\mathrm{MeSH}$, medical subject heading; $\mathrm{MH}$, subject heading. 
Table 2 Studies included in the review

\begin{tabular}{|c|c|c|c|c|c|}
\hline Study & Year & Country & Sample size & Foot complications & Adherence dimensions investigated \\
\hline Arts et al ${ }^{17}$ & 2014 & the Netherlands & 153 & $\begin{array}{l}\text { All had sensory neuropathy and a } \\
\text { healed ulcer }\end{array}$ & $\begin{array}{l}\text { Patient, therapy, condition, social/ } \\
\text { economic circumstances }\end{array}$ \\
\hline Breuer $^{18}$ & 1994 & Germany & 85 & $\begin{array}{l}\text { All had sensory neuropathy and a } \\
\text { healed ulcer }\end{array}$ & $\begin{array}{l}\text { Patient, therapy, condition, social/ } \\
\text { economic circumstances, health system }\end{array}$ \\
\hline Chantelau and $\mathrm{Haage}^{3}$ & 1994 & Germany & 51 & All had a healed ulcer & Patient, condition \\
\hline Churchman ${ }^{19}$ & 2008 & UK & $20^{\mathrm{a}}$ & All had a healed ulcer & Patient \\
\hline Macfarlane and Jensen ${ }^{20}$ & 2003 & USA & 50 & $62 \%$ had a history of foot complications & Patient, therapy, condition \\
\hline Waaijman et $\mathrm{al}^{5}$ & 2013 & the Netherlands & 107 & $\begin{array}{l}\text { All had sensory neuropathy and a } \\
\text { healed ulcer }\end{array}$ & $\begin{array}{l}\text { Patient, therapy, condition, social/ } \\
\text { economic circumstances }\end{array}$ \\
\hline
\end{tabular}

Note: ${ }^{T}$ The study had 51 participants but only 20 had been prescribed therapeutic shoes.

care were compared between the 37 interviewees classified as adherent (those who reported that they wore therapeutic shoes for $>60 \%$ of daytime hours) and the 14 interviewees classified as nonadherent.

Churchman ${ }^{19}$ sent a questionnaire to people who had had a foot ulcer within the past 2 years, and 20 of the respondents had been prescribed therapeutic shoes. The relation between sex and self-reported use of therapeutic shoes (days per week and hours per day) was investigated.

Macfarlane and Jensen ${ }^{20}$ surveyed people who had been provided with therapeutic shoes and investigated correlations between the 50 respondents' self-reported adherence and age, diabetes duration, and perceptions of their foot condition and shoes.

Waaijman et $\mathrm{al}^{5}$ investigated adherence in 107 people with therapeutic shoes, using a temperature monitor in the shoe and a step activity monitor strapped to the leg. The association between adherence and factors related to the person, condition, shoes, and social situation was investigated in a multiple regression analysis.

The results are summarized in Table 3 and the main findings are discussed further according to the five adherence dimensions proposed by the World Health Organization. ${ }^{13}$ Many factors were investigated in only one study and most associations were nonsignificant.

\section{Patient-related factors}

Sex differences in attitudes toward therapeutic shoes have been reported in the literature, with women being less satisfied than men with the choices of shoe style and color. ${ }^{1}$ From this, it would be expected that women wear their therapeutic shoes to a lesser degree than men do. This was investigated

Table 3 Summary of results of the included studies: associations with adherence to wearing therapeutic shoes

\begin{tabular}{|c|c|c|}
\hline Study & Factors associated with adherence ${ }^{a}$ & Factors not associated with adherence \\
\hline Arts et $\mathrm{al}^{17}$ & Perceived benefit of shoes at home $(+, P=0.045, \mathrm{OR}$ I.272) & $\begin{array}{l}\text { Sex, age, BMI, shoe attributes, }{ }^{b} \text { overall appreciation } \\
\text { of the shoes, previous use of therapeutic shoes, } \\
\text { perceived benefit of shoes at work, diabetes } \\
\text { duration, diabetes type, foot deformity, }{ }^{\mathrm{c}} \text { vibration } \\
\text { perception threshold, education level }\end{array}$ \\
\hline Breuer $^{18}$ & $\begin{array}{l}\text { Age }(+, P<0.05) \text {, type } 2 \text { diabetes }(+, P<0.05) \text {, no perceived } \\
\text { control over ulcer recurrences }(+, P<0.05) \text {, feet perceived as } \\
\text { very sick }(+, P<0.0 \mathrm{I}) \text {, perceived overall health }(-, P<0.05) \text {, renal } \\
\text { replacement therapy }(-, P<0.00 \mathrm{I}) \text {, minor amputation } \\
(+, P<0.0 \mathrm{I}) \text {, preference for therapeutic shoes rather than } \\
\text { clothing }(+, P<0.0 \mathrm{I}) \text {, TV }(+, P<0.0 \mathrm{I}) \text { or traveling }(+, P<0.0 \mathrm{I})\end{array}$ & $\begin{array}{l}\text { Sex, shoe appearance, diabetes duration, blindness, } \\
\text { previous painless ulcers, living alone, being } \\
\text { unemployed, leaving home less than once per day, } \\
\text { unable to walk }>15 \text { minutes, perceived sensitivity } \\
\text { in feet, sufficiently informed about foot disease }\end{array}$ \\
\hline Chantelau and Haage $^{3}$ & Frequency of foot care $(+, P<0.0 \mathrm{I})$ & Sex, history of $>$ one ulcer \\
\hline Churchman ${ }^{19}$ & (None) & Sex \\
\hline Macfarlane and Jensen ${ }^{20}$ & $\begin{array}{l}\text { Belief that wearing therapeutic shoes is important to prevent } \\
\text { complications }(+, P=0.0002)\end{array}$ & $\begin{array}{l}\text { Age, belief that therapeutic shoes are important, } \\
\text { diabetes duration, perceived severity of foot } \\
\text { complications, perceived severity of foot condition }\end{array}$ \\
\hline Waaijman et $\mathrm{al}^{5}$ & $\begin{array}{l}\text { BMI }(-, P=0.066, \beta=-0.747) \text {, better shoe appearance }(+, P=0.032 \text {, } \\
\beta=I .975) \text {, more severe foot deformity }(+, P=0.034, \beta=6.831) \text {, } \\
\text { variation in daily step count }(+, P=0.033, \beta=3.655)\end{array}$ & $\begin{array}{l}\text { Sex, age, shoe type, shoe comfort, diabetes type, } \\
\text { diabetes duration, PAD grade, HbAIc, cumulative } \\
\text { past ulcer months, major amputation, daily step } \\
\text { count, education level, living alone, being employed }\end{array}$ \\
\hline
\end{tabular}

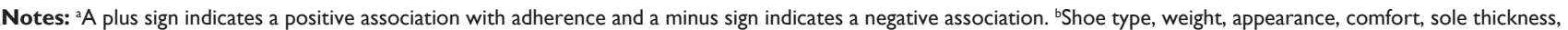
stability, durability, ease of donning/doffing, maintenance. Including minor amputations.

Abbreviations: $\beta$, regression coefficient; BMI, body mass index; OR, odds ratio; PAD, peripheral arterial disease; HbAIc, Hemoglobin AIc. 
in five studies, ${ }^{3,5,17-19}$ but no association between sex and adherence was found. Age has previously been found to be associated with adherence to physical activity and diet in people with diabetes. ${ }^{13}$ Four studies ${ }^{5,17,18,20}$ investigated the association between adherence to wearing therapeutic shoes and age, of which one study ${ }^{18}$ found an association: the nonadherent group was younger than the adherent group.

Two studies ${ }^{18,20}$ investigated the association between adherence and perceived severity of the foot condition, but only one ${ }^{18}$ found a positive association. Surprisingly, and counterintuitively, Breuer ${ }^{18}$ found that the proportion of people who expected ulcer recurrences whatever they did was higher in the adherent group than in the nonadherent group.

An association could be expected between the value the person puts on the shoes and adherence, but the results were conflicting: one study ${ }^{18}$ found that the proportion of interviewees who would have therapeutic shoes rather than clothing, $\mathrm{TV}$, or traveling was higher in the adherent group, whereas another study ${ }^{17}$ found no association between overall appreciation of the shoes and adherence. It has been hypothesized that perceived benefits are important for an individual's decision to use therapeutic shoes and other assistive devices. ${ }^{21,22}$ One study ${ }^{17}$ found an association between perceived benefit of therapeutic shoes and adherence (although not significant in the case of benefit in the workplace, which might be attributed to the fact that few of the participants were working). Macfarlane and Jensen ${ }^{20}$ found that respondents who believe that wearing therapeutic shoes is important to prevent complications also wear them to a higher degree. Interestingly, the latter study did not find any association between adherence and the more general belief that therapeutic shoes are important. It might be the case that adherence is determined by an individual's personal beliefs about his or her own feet and shoes, rather than by general beliefs about foot disease and therapeutic shoes. To the best of our knowledge, the study by Macfarlane and Jensen ${ }^{20}$ is the only one that has investigated whether the person's belief in the main aim of prescribing therapeutic shoes, that is, reducing ulceration risks, influences adherence. Risk perception is an interesting aspect, given that many people with diabetes are not aware that they have sensory neuropathy ${ }^{23}$ or do not consider it to be a risk factor for foot ulcers. ${ }^{14}$ In the study by Macfarlane and Jensen, ${ }^{20}$ most respondents felt that their foot condition was better than that of most other people with diabetes, even though $62 \%$ had a history of foot complications. Further studies are needed on how to educate and inform patients about risks and risk management. These risk education programs should observe that some people with foot ulcers may have cognitive difficulties ${ }^{24}$ and therefore need adapted teaching. An interesting avenue for patient education is the development of activity monitors and temperature sensors to measure adherence and provide feedback to patients. ${ }^{25}$

\section{Therapy-related factors}

Attributes of the therapeutic shoes, such as appearance, comfort, and weight, are common sources of complaints and could therefore be expected to influence adherence. ${ }^{20}$ Three studies $^{5,17,18}$ considered shoe appearance, and one of them ${ }^{5}$ found an association with adherence. Two studies ${ }^{5,17}$ investigated other shoe attributes, such as shoe type and comfort, and found no association with adherence. The reason might be that the individuals and shoe types used are too heterogeneous to find common patterns.

\section{Condition-related factors}

People with diabetic foot complications often suffer from significant comorbidity ${ }^{26}$ and thus undergo several simultaneous health treatments. Five studies ${ }^{3,5,17,18,20}$ investigated whether health conditions (including diabetes and related complications) and treatments influence adherence: diabetes duration consistently showed no association with adherence, $, 17,18,20$ while diabetes type was associated with adherence in one ${ }^{18}$ of three studies. ${ }^{5,17,18}$ Four studies ${ }^{3,5,17,18}$ investigated whether foot status influenced adherence: ulcer history consistently showed no association with adherence, ${ }^{3,5,18}$ while the results were conflicting regarding the presence of minor amputation ${ }^{5,17,18}$ and severity of foot deformity (including minor amputations). ${ }^{5,17}$ Only one study ${ }^{5}$ investigated the history of major amputation and found no association with adherence. One $\mathrm{O}^{5}$ of two studies $^{5,17}$ investigating body mass index found a negative association with adherence.

Some authors ${ }^{27,28}$ have hypothesized that sensory neuropathy reduces adherence to wearing offloading devices. The rationale is that pain is an important motivator for an individual to offload pressure on an ulcer, and with sensory neuropathy this motivator is diminished or absent. Neither Arts et $\mathrm{al}^{17}$ nor Breuer ${ }^{18}$ found any association between sensory neuropathy and adherence, but as the participants did not have ulcers at the time of the study and were not asked specifically about pain, it is not possible to corroborate or refute the hypothesis from these results. There are currently no studies on people without active ulcers investigating pain as a direct motivator for adherence, that is, the difference in pain between when wearing therapeutic and other shoes (or no shoes). 


\section{Health system-related factors}

One study ${ }^{18}$ investigated the association between adherence and the extent to which interviewees felt sufficiently informed about the foot disease, but found no association. Some authors have hypothesized that the payment structures for therapeutic shoes might influence adherence. Soorikumaran ${ }^{29}$ hypothesized that people would wear the shoes more if they had to pay a fee for them, in accordance with the sunk-cost effect, which is manifested in a greater tendency to continue an endeavor (in this case, wearing therapeutic shoes) once an investment has been made. ${ }^{30,31}$ On the other hand, a fee might be an obstacle for some people to obtain therapeutic shoes at all. ${ }^{14}$ To the authors' knowledge, the hypothesis about the impact of fees on adherence to wearing therapeutic shoes has not been studied empirically. Neither has any study investigated the effects of presumably important health systemrelated factors, such as the reimbursement system, frequency of follow-up, continuity of care, and communication style of the shoe provider.

\section{Social and economic factors}

Three studies ${ }^{5,17,18}$ investigated different social factors and found no impact on adherence from living alone, ${ }^{5,18}$ employment, ${ }^{5,18}$ or education level. ${ }^{5,17}$ None of the studies investigated whether social support influences adherence.

The scarcity of studies investigating social and economic factors is surprising, given the impact of social context on fashion and clothing. In rural areas in developing countries, it is common to walk barefoot outside, even among people with diabetes, ${ }^{32,33}$ and there are large variations across countries in the extent and type of shoes that are worn indoors. Some professions demand that employees wear protective shoes or shoes with a certain appearance, and therapeutic shoes might reveal the individual's diabetes diagnosis to other people, which can be unwelcome. ${ }^{22,34}$ Thus, there is a need to include social, professional, and other environmental factors in future studies on adherence. Simply instructing people to wear their therapeutic shoes all the time without taking context into account is probably not a successful strategy. There is a need to "tailor the treatment to the patient's lifestyle, not the other way around." 35

\section{Discussion}

Studies to date have mostly focused on adherence to wearing therapeutic shoes in relation to the patient's perceptions, therapy (eg, shoe comfort) and condition (diabetes and its complications), with little emphasis given to factors related to the patient's social and economic circumstances or the health system. Many factors have only been investigated in a single study and most have turned out to be nonsignificant. There are too few studies to draw any firm conclusions at present, but there is some evidence (three to five studies) for not using sex, diabetes duration, or ulcer history as predictors of adherence. The evidence for or against the other factors is weak (only one or two studies) or conflicting.

It might seem counterintuitive that complaints that are common in qualitative studies and clinical practice, such as shoe appearance, in most cases are not associated with adherence. The reason might be that people give different weight to different factors. Some do not wear the shoes because they are unattractive, while others wear the shoes even though they are unattractive, because they perceive some other benefit of wearing them. The results of this review also contrast with studies on mixed samples of people with diabetes and other health conditions, where sex and opinions about shoe attributes have been associated with adherence levels. ${ }^{36,37}$ However, the results are difficult to compare with the current review, as shoes are prescribed for different reasons according to the diagnosis, for example, ulcer prevention for people with diabetes and pain relief for people with rheumatoid arthritis.

The results on objective and subjective foot status were mixed, with some studies supporting an association with adherence and some studies not. Knowles and Boulton ${ }^{1}$ state that the person needs to be convinced of the severity of the foot condition and the benefit of wearing therapeutic shoes. We agree and pose the following hypothesis: adherence to wearing therapeutic shoes is positively influenced by the foot condition only if two prerequisites are fulfilled: 1) the person thinks that the foot condition is a problem (which might be more apparent with a minor amputation than with a healed ulcer); and 2) the person believes that wearing therapeutic shoes solves this problem better than wearing other shoes (or no shoes). Interestingly, two studies ${ }^{17,20}$ found that the perceived benefit of wearing therapeutic shoes was associated with higher adherence. This is in line with a theory of adherence to using assistive technology, emphasizing the impact on adherence of perceived benefits of using the technology in comparison with other interventions..$^{21}$ Therefore, we suggest that future studies should ask people specifically about perceived costs and benefits of wearing therapeutic shoes in comparison with other shoes (or no shoes).

There are several limitations with the included studies and, therefore, we did not find it meaningful to grade the quality of the studies. All studies were observational cross-sectional studies, many studies had small samples of 
participants and the studies defined and measured adherence in different ways; these weaknesses made it more difficult to draw conclusions about the influence of various factors on adherence. Four of the studies only used univariate analysis, which makes the results more vulnerable to confounding. Finally, all studies were conducted in North America or Western Europe, limiting the generalizability of the results. Future studies should preferably be conducted in different cultural settings and use an experimental, longitudinal study design, and multivariate analysis to gain more robust evidence for causal mechanisms. A limitation of this review was that the search was restricted to publications in English. Hence, we cannot exclude the possibility that we might have missed some relevant studies, especially studies conducted outside North America and Western Europe.

In general, studies have not yet been very successful in finding predictors of adherence, which might have three possible explanations. First, researchers might have focused on the wrong factors and need to broaden the focus to include more factors related to the patient's social and economic situation and the health system. Second, researchers might have used the wrong perspective, for example, focusing on perceptions of the therapeutic shoes per se instead of perceptions of the relative costs and benefits of wearing therapeutic shoes compared with other shoes (or no shoes). ${ }^{21,22}$ Third, researchers might have paid too little attention to the distinction between group and individual-level predictors of adherence. People with diabetic foot complications are a heterogeneous group and the reasons for choosing to wear or not wear therapeutic shoes might vary so strongly between individuals that predictors for adherence can only exist on the level of the individual or subgroup, and not on the level of the whole group. Regardless of whether there are group-level predictors that have yet to be found or whether such general predictors do not exist, there is a need for a deeper understanding of the multifaceted nature of adherence as phenomenon. A model to aid such understanding is presented in the following section.

\section{A model of adherence to wearing therapeutic shoes}

We constructed a seesaw model to illustrate how different factors impact a person's or a group of people's adherence to wearing therapeutic shoes (Figure 1). The factors are represented by boxes, whose position on the seesaw represents the direction of impact (toward adherence or nonadherence) and the size of the boxes represents the relative weights of different factors. The net effect of the factors is illustrated by the tipping of the seesaw toward adherence or nonadherence.

\section{B}

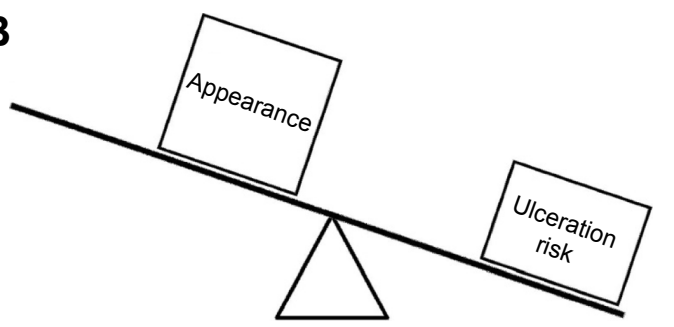

Wear other shoes (nonadherence)
Wear therapeutic shoes (adherence)
Wear therapeutic shoes (adherence)
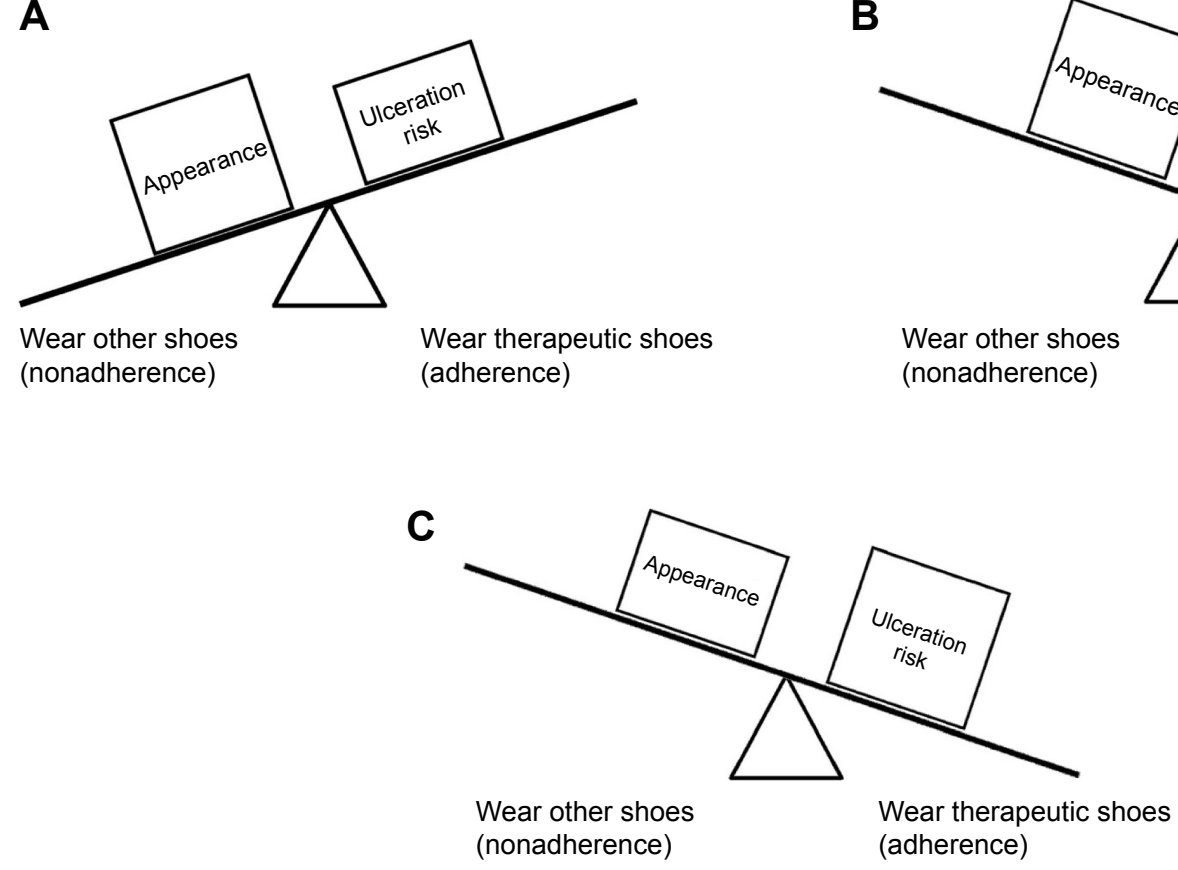

Figure I A seesaw model illustrating how different factors affect adherence to wearing therapeutic shoes.

Notes: Box position represents the direction of the effect (toward adherence or nonadherence) and box size represents the weight of the factor. (A) A person believing that wearing therapeutic shoes reduces ulceration risks somewhat compared to other shoes, but this is outweighed by the fact that he finds his therapeutic shoes less attractive, a factor he gives more weight to. The net result is low adherence to wearing his therapeutic shoes. (B) The same person as in (A), after being convinced that wearing therapeutic shoes reduces ulceration risks substantially compared to other shoes. (C) The same person as in (A), after having reprioritized shoe appearance and ulceration risks. 
Importantly, the factors (boxes), their direction of influence (box position), and the weight given to them (box size) are all seen from the perspective of the person with the foot condition. For example, it is the perception of the extent that therapeutic shoes reduce ulceration risks that influences adherence, not whether the shoes objectively do reduce the risks.

The model can be used to understand how, and in what way, perceptions influence adherence (or nonadherence) to wearing therapeutic shoes. Furthermore, the model can be used to highlight what actions can be taken to improve adherence. We can influence adherence (tipping of the seesaw) by changing the factors' direction of influence (box positions), relative weights (box sizes), or a combination of the two. The lines of action are illustrated with a fictive case: a middleaged man with a recently healed plantar ulcer. Note that the case is strongly simplified and only includes two factors to illustrate the use of the model. Although the man believes that wearing therapeutic shoes reduces the risk of ulceration compared with other shoes, he believes that the difference is small and this is outweighed by the fact that he finds his therapeutic shoes less attractive, a factor he gives more weight to. The net result is nonadherence (Figure 1A). The first option to improve his adherence would be to influence his perceptions of ulceration risks when wearing therapeutic and other shoes. Mueller et $\mathrm{al}^{38}$ demonstrated how visualizations of plantar pressures can be used to educate people with sensory neuropathy about the offloading effect of therapeutic shoes because they no longer experience the sensation of pressure on the foot. If the person is convinced that wearing therapeutic shoes substantially reduces ulceration risks compared with other shoes, this will give a stronger motivation for adherence (Figure 1B). The second option to improve the man's adherence would be to facilitate the process of adapting to wearing therapeutic shoes. A qualitative case study by Paton et $\mathrm{al}^{39}$ illustrates the dynamic process of adherence, in which some individuals shift priorities over time, resulting in higher adherence. This process can be viewed as a shift from the everyday perspective of shoes as items of clothing (emphasizing appearance), to a professional's perspective of shoes as medical devices (emphasizing ulcer prevention). ${ }^{39}$ By understanding where an individual is in the process of adaptation, we might be able to facilitate the process and thereby improve adherence (Figure 1C).

Obviously, the model is a simplification of the real-life situation where a multitude of factors may interact and influence adherence. Nevertheless, the case illustrates that the model can highlight different lines of action that can be taken to improve adherence. Notably, the two examples of how to improve the man's adherence do not include (but do not exclude) any improvement in the appearance of the shoes, although this was his self-reported reason for not wearing them.

\section{Conclusion}

There are too few studies to draw any definitive conclusions about factors associated with adherence to wearing therapeutic shoes. There is some evidence for not using sex, diabetes duration, or ulcer history as predictors of adherence. High-quality studies are needed, simultaneously investigating the impact on adherence of a broader range of factors, including those related to the health system and the patient's social and economic situation. The framework of perceived costs and benefits of wearing therapeutic shoes compared with other shoes or no shoes is an interesting starting point for further inquiry. A model of adherence is proposed that can hopefully support further research and development in the field.

\section{Acknowledgment}

This study was supported by Region Örebro County, Sweden.

\section{Disclosure}

The authors report no conflicts of interest in this work.

\section{References}

1. Knowles EA, Boulton AJ. Do people with diabetes wear their prescribed footwear? Diabet Med. 1996;13(12):1064-1068.

2. Bus SA, Waaijman R, Arts M, et al. Effect of custom-made footwear on foot ulcer recurrence in diabetes: a multicenter randomized controlled trial. Diabetes Care. 2013;36(12):4109-4116.

3. Chantelau E, Haage P. An audit of cushioned diabetic footwear: relation to patient compliance. Diabet Med. 1994;11(1):114-116.

4. Paton JS, Roberts A, Bruce GK, Marsden J. Patients' experience of therapeutic footwear whilst living at risk of neuropathic diabetic foot ulceration: an interpretative phenomenological analysis (IPA). J Foot Ankle Res. 2014;7(1):16.

5. Waaijman R, Keukenkamp R, de Haart M, Polomski WP, Nollet F, Bus SA. Adherence to wearing prescription custom-made footwear in patients with diabetes at high risk for plantar foot ulceration. Diabetes Care. 2013;36(6):1613-1618.

6. Armstrong DG, Lavery LA, Kimbriel HR, Nixon BP, Boulton AJ. Activity patterns of patients with diabetic foot ulceration: patients with active ulceration may not adhere to a standard pressure off-loading regimen. Diabetes Care. 2003;26(9):2595-2597.

7. McCabe CJ, Stevenson RC, Dolan AM. Evaluation of a diabetic foot screening and protection programme. Diabet Med. 1998;15(1): $80-84$.

8. Bus SA, Armstrong DG, van Deursen RW, Lewis JE, Caravaggi CF, Cavanagh PR. IWGDF guidance on footwear and offloading interventions to prevent and heal foot ulcers in patients with diabetes. Diabetes Metab Res Rev. 2016;32(Suppl 1):25-36. 
9. Hingorani A, LaMuraglia GM, Henke P, et al. The management of diabetic foot: A clinical practice guideline by the Society for Vascular Surgery in collaboration with the American Podiatric Medical Association and the Society for Vascular Medicine. J Vasc Surg. 2016; 63(2 Suppl):3S-21S.

10. Apelqvist J, Larsson J, Agardh CD. Long-term prognosis for diabetic patients with foot ulcers. J Intern Med. 1993;233(6):485-491.

11. Peters EJ, Armstrong DG, Lavery LA. Risk factors for recurrent diabetic foot ulcers: site matters. Diabetes Care. 2007;30(8):2077-2079.

12. Pound N, Chipchase S, Treece K, Game F, Jeffcoate W. Ulcer-free survival following management of foot ulcers in diabetes. Diabet Med. 2005;22(10):1306-1309.

13. Sabaté E. Adherence to Long-Term Therapies: Evidence for Action. Geneva: World Health Organization; 2003.

14. van de Weg B. Compliance with orthopaedic footwear in patients with diabetes. Diabetic Foot J. 2002;5(1):32-36.

15. Baker N, Leatherdale B. Audit of special shoes: are they being worn? Diabetic Foot J. 1999;2(3):100-104.

16. Paton JS, Roberts A, Bruce GK, Marsden J. Does footwear affect balance? the views and experiences of people with diabetes and neuropathy who have fallen. J Am Podiatr Med Assoc. 2013;103(6):508-515.

17. Arts ML, de Haart M, Bus SA, Bakker JP, Hacking HG, Nollet F. Perceived usability and use of custom-made footwear in diabetic patients at high risk for foot ulceration. J Rehabil Med. 2014;46(4):357-362.

18. Breuer U. Diabetic patient's compliance with bespoke footwear after healing of neuropathic foot ulcers. Diabet Metab. 1994;20(4):415-419.

19. Churchman N. A retrospective audit of footwear use by high-risk individuals in North Derbyshire. Diabetic Foot J. 2008;11(1):10-18.

20. Macfarlane DJ, Jensen JL. Factors in diabetic footwear compliance. J Am Podiatr Med Assoc. 2003;93(6):485-491.

21. Lenker JA, Paquet VL. A new conceptual model for assistive technology outcomes research and practice. Assist Technol. 2004;16(1):1-10.

22. van Netten JJ, Dijkstra PU, Geertzen JH, Postema K. What influences a patient's decision to use custom-made orthopaedic shoes? BMC Musculoskelet Disord. 2012;13:92.

23. Bongaerts BW, Rathmann W, Heier M, et al. Older subjects with diabetes and prediabetes are frequently unaware of having distal sensorimotor polyneuropathy: the KORA F4 study. Diabetes Care. 2013;36(5): 1141-1146.

24. Natovich R, Kushnir T, Harman-Boehm I, et al. Cognitive dysfunction: part and parcel of the diabetic foot. Diabetes Care. 2016;39(7): 1202-1207.
25. Bus SA, Waaijman R, Nollet F. New monitoring technology to objectively assess adherence to prescribed footwear and assistive devices during ambulatory activity. Arch Phys Med Rehabil. 2012;93(11):2075-2079.

26. Gershater MA, Londahl M, Nyberg P, et al. Complexity of factors related to outcome of neuropathic and neuroischaemic/ischaemic diabetic foot ulcers: a cohort study. Diabetologia. 2009;52(3):398-407.

27. Van De Weg FB, Van Der Windt DA, Vahl AC. Wound healing: total contact cast vs custom-made temporary footwear for patients with diabetic foot ulceration. Prosthet Orthot Int. 2008;32(1):3-11.

28. Helm PA, Walker SC, Pullium GF. Recurrence of neuropathic ulceration following healing in a total contact cast. Arch Phys Med Rehabil. 1991;72(12):967-970.

29. Soorikumaran S. Surgical footwear. BMJ. 1989;299(6705):976.

30. Arkes HR, Blumer C. The psychology of sunk cost. Organ Behav Hum Dec. 1985;35(1):124-140.

31. Christensen-Szalanski JJ, Northcraft GB. Patient compliance behavior: the effects of time on patients' values of treatment regimens. Soc Sci Med. 1985;21(3):263-273.

32. Jayasinghe SA, Atukorala I, Gunethilleke B, Siriwardena V, Herath SC, De Abrew K. Is walking barefoot a risk factor for diabetic foot disease in developing countries? Rural Remote Health. 2007;7(2):692.

33. Shankhdhar K, Shankhdhar LK, Skankhdhar U. Diabetic foot care in the land of no podiatrists. WCET J. 2008;28(1):20-23.

34. Johnson M, Newton P, Goyder E. Patient and professional perspectives on prescribed therapeutic footwear for people with diabetes: a vignette study. Patient Educ Couns. 2006;64(1-3):167-172.

35. Aronson JK. Compliance, concordance, adherence. Br JClin Pharmacol. 2007;63(4):383-384

36. van Netten JJ, Jannink MJ, Hijmans JM, Geertzen JH, Postema K. Long-term use of custom-made orthopedic shoes: 1.5-year follow-up study. J Rehabil Res Dev. 2010;47(7):643-649.

37. van Netten JJ, Jannink MJ, Hijmans JM, Geertzen JH, Postema K. Use and usability of custom-made orthopedic shoes. JRehabil Res Dev. 2010; 47(1):73-81.

38. Mueller MJ, Smith KE, Commean PK, Robertson DD, Johnson JE. Use of computed tomography and plantar pressure measurement for management of neuropathic ulcers in patients with diabetes. Phys Ther. 1999; 79(3):296-307.

39. Paton J, Roberts A, Glasser S, Collings R, Marsden J. “All I wanted was a pair of shoes": a qualitative case study. Diabetic Foot J. 2014;17(3): $100-106$.
Patient Preference and Adherence

\section{Publish your work in this journal}

Patient Preference and Adherence is an international, peer-reviewed, open access journal that focuses on the growing importance of patient preference and adherence throughout the therapeutic continuum. Patient satisfaction, acceptability, quality of life, compliance, persistence and their role in developing new therapeutic modalities and compounds to optimize

\section{Dovepress}

clinical outcomes for existing disease states are major areas of interest for the journal. This journal has been accepted for indexing on PubMed Central. The manuscript management system is completely online and includes a very quick and fair peer-review system, which is all easy to use. Visit http://www. dovepress.com/testimonials.php to read real quotes from published authors. 